\title{
Urgences
}

\section{Comptes à rebours}

\section{Michel Savard}

Numéro 11, 3e trimestre 1984

URI : https://id.erudit.org/iderudit/025170ar

DOI : https://doi.org/10.7202/025170ar

Aller au sommaire du numéro

Éditeur(s)

Urgences

ISSN

0226-9554 (imprimé)

1927-3924 (numérique)

Découvrir la revue

Citer ce document

Savard, M. (1984). Comptes à rebours. Urgences, (11), 21-32.

https://doi.org/10.7202/025170ar

Ce document est protégé par la loi sur le droit d'auteur. L'utilisation des services d'Érudit (y compris la reproduction) est assujettie à sa politique d'utilisation que vous pouvez consulter en ligne.

https://apropos.erudit.org/fr/usagers/politique-dutilisation/
Cet article est diffusé et préservé par Érudit.

Érudit est un consortium interuniversitaire sans but lucratif composé de l’Université de Montréal, l'Université Laval et l'Université du Québec à Montréal. Il a pour mission la promotion et la valorisation de la recherche. https://www.erudit.org/fr/ 


\section{MICHEL SAVARD}

\section{Comptes à rebours}

densément rigide

le train de l'aube écrase

l'acier des rails nous y restons ligotés

même maintenant que le jour a repris le collier de nier les fulgurances de l'obscur comme si rien n'avait hurlé même à présent nous pressentons nous savons le meilleur du pire et qu'après Tout c'est la nuit 
$10 \ldots$

ce soir on évacue la lune

nous gémissons au léger choc

de I'arrimage inattendu puis

basculons dans un vide fouetté d'arbres froids nous retrouvant semblables investis de cruauté avec des doigts qui savent tracer sans nous les mêmes pentagrammes sur les terres anciennes de nos corps aliénés 
$9 .$.

du moins sommes-nous

quand tout se précipite

solidaires dans notre asservissement

au feu que jamais nul n'assouvit

du moins pressentons-nous ensemble

l'après et l'exil aux rives lavées

de n'importe où dans le quelconque

chacun devant sa propre terreur

mutilé

à rendre compte 
$8 \ldots$

la pointe chaude de l'iceberg

t'allume de ce qu'elle projette

de lumière haletante entre nous

tu te plais à prolonger

ce passage vers l'écart

et moi savourant ton aisance

aux points sensibles des ondes

je $\mathrm{m}^{\prime}$ engage sans armes

sur tes tracés 
nous buvons goulûment

à la vigne du bien et du mal nous sentant à nouveau devenir semblables à Dieu déjà nos coupes ne tremblent plus nous y versons davantage sachant imminente notre dépossession 
$6 \ldots$

soudain

nos vêtements se dissolvent

comment I'expliques-tu

ou que nos corps se distendent

sous l'action de baves intérieures

bien qu'aucune mémoire ne subsiste

de ce gué vers le curare 
$5 \ldots$

quand j'impose les mains sur tes lieux rubescents

je sens que la tourmente cambre plus que ton échine cet orgueil duquel jamais tu ne déroges sans coup férir 
$4 \ldots$

cette rage toutes les poses

que tu lui fais assumer toi

qui t'écartèles toi qui t'accroupis

toi qui suintes sur mes yeux

et sur mes lèvres grasses 
$3 \ldots$

tu fais peu d'autres gestes

que ceux qui t'écraseront là

contre ton cri je conçois la haine

que tes doux yeux dégorgent 
$2 \ldots$

poutrelle dans I'oeil vibrant de ton tronc je bats l'espace rouge fer oui je t'aime ça 
$1 \ldots$

forcené sangloter à te briser

des dents la nuque frénétique 
nos vestiges encore dans cet autre non-lieu

Rivière-du-Loup, décembre 1982 